\title{
Inhibition of Diabetes Mellitus-Induced Knee Joint Injury in Rats by a Combination of Metformin and Captopril
}

\author{
Inhibición de la Lesión de la Articulación de la Rodilla Inducida por Diabetes \\ Mellitus en Ratas Mediante una Combinación de Metformina y Captopril
}

\author{
Mahmoud H. El-Bidawy ${ }^{1,2}$;Bahjat Al-Ani ${ }^{3}$; Abo Bakr Omar Hussain ${ }^{4}$; \\ Sameer Al-Ghamdi ${ }^{5}$; Khaled K. Aldossari ${ }^{5}$ \& Mohamed A. Haidara ${ }^{2}$
}

\begin{abstract}
EL-BIDAWY, M. H.; AL-ANI, B.; HUSSAIN, A. B.O.; AL-GHAMDI, S.; ALDOSSARI, K. K. \& HAIDARA, M. A. Inhibition of diabetes mellitus-induced knee joint injury in rats by a combination of metformin and captopril. Int. J. Morphol., 39(3):747-753, 2021.
\end{abstract}

SUMMARY: Osteoarthritis (OA) is an inflammatory disease that damages the joints and affects millions of people worldwide. The potential inhibitory effects of the antidiabetic drug metformin combined with captopril, the angiotensin-converting enzyme inhibitor, on diabetes-induced damage to the knee joint articular cartilage associated with the inhibition of glycemia, dyslipidemia, and inflammation has not been investigated before. Therefore, we induced diabetes in rats using high carbohydrate and fat diets and a single injection of streptozotocin $(50 \mathrm{mg} / \mathrm{kg})$. The protective group of rats was pre-treated with combined daily doses of metformin (Met; $200 \mathrm{mg} / \mathrm{kg}$ body weight) and captopril (Cap; $150 \mathrm{mg} / \mathrm{kg}$ body weight) for 14 days before diabetic induction and continued on metformin and resveratrol until the end of the experiment at week 12. Harvested tissues obtained from knee joints were prepared for basic histology staining with haematoxylin and eosin (H\&E) and examined under light microscopy. Representative H\&E images showed that OA was developed in the diabetic rats as demonstrated by a profound damage to the knee joints such as irregular eroded and a sharp decrease in the thickness of the articular cartilage surface and abnormal remodeling of the subchondral bone that were substantially ameliorated by Met+Cap. Met+Cap also significantly $(\mathrm{p}<0.05)$ reduced blood levels of glucose, glycated hemoglobin (HbA1c), dyslipidemia, and the inflammatory biomarkers, high sensitivity C-reactive protein (hs-CRP), interleukin-6 (IL-6), and tumour necrosis factor-alpha (TNF- $\alpha$ ) induced by diabetes. In addition, a significant $(p \leq 0.0014)$ correlation between the articular cartilage thickness and the blood levels of glucose, HbA1c,triglyceride (TG), low density lipoprotein-cholesterol (LDL-C), high density lipoproteincholesterol (HDL-C), and hs-CRP were observed. Thus, we demonstrate that Met+Cap effectively protect the knee joint against injuries induced secondary to diabetes in rats, possibly due to the inhibition of glycemia, dyslipidemia, and biomarkers of inflammation.

KEY WORDS: Osteoarthritis; Diabetes; Knee joint; Metformin; Captopril; Rat model.

\section{INTRODUCTION}

Upregulation of inflammation and oxidative stress by hyperglycemia represents the root cause of diabetic complications (Shoelson et al., 2006). The link between diabetes and osteoarthritis (OA) is well established and OA secondary to diabetes affects millions of people around the globe (Pottie et al., 2006). It can lead to disability due to limitations in the movement of the affected joints, mostly as a consequence of inflammation and destruction of the knee and hip joints (Scanzello \& Goldring, 2012). The knee joint is affected by OA, which causes inflammation and progressive destruction to the structure of the knee joint articular cartilage (Hayami, 2008). This leads to joint pain, redness and swelling, and decreased joint movement, which mostly affects older people (Hayami). In addition, the development of OA secondary to diabetes is involved inflammatory mediators, chronic low-grade inflammation,

\footnotetext{
${ }^{1}$ Department of BMS, Division of Physiology, College of Medicine, Prince Sattam IbinAbdulaziz University, Al-Kharj 11942, Saudi Arabia.

${ }^{2}$ Department of Physiology, Kasr Al-Aini Faculty of Medicine, Cairo University, Cairo, Egypt.

${ }^{3}$ Department of Physiology, College of Medicine, King Khalid University, Abha, Saudi Arabia.

${ }^{4}$ Department of Cardiology, College of Medicine,Prince Sattam Ibin Abdulaziz University, Al-Kharj 11942, Saudi Arabia.

${ }_{5}^{5}$ Department of Family \&Community medicine, College of Medicine, Prince Sattam Ibin Abdulaziz University, Al-Kharj 11942, Saudi Arabia. SOURCE OF FUNDING: This research was funded by the Prince Sattam Ibin Abdulaziz University, Al-Kharj 11942, Saudi Arabia, through the Research Funding Program (Grant No:2019/03/11768).

ORCID:Bahjat Al-Ani: http://orcid.org/0000-0001-5773-1160
} 
EL-BIDAWY, M. H.; AL-ANI, B.; HUSSAIN, A. B.O.; AL-GHAMDI, S.; ALDOSSARI, K. K. \& HAIDARA, M. A. Inhibition of diabetes mellitus-induced knee joint injury in rats by a combination of metformin and captopril. Int. J. Morphol., 39(3):747-753, 2021.

and adipokines (Berenbaum, 2011). In diabetes, accumulation of advanced glycation end-products (AGEs), which are accepted biomarkers in aging and diabetes (Vistoli et al., 2013) in the OA cartilage induces injury via activation of their specific receptor, RAGE, which plays a proinflammatory and procatabolic role on chondrocytes and synovial cells and reduces the synthesis of collagen (Moussa, 2008).

The pleotropic effects of the antidiabetic drug metformin (Cicero et al., 2012) and the angiotensinconverting enzyme inhibitor, captopril (Al-Hashem et al., 2019b) make these agents useful medicine in many diseases. For example, (i) metformin was shown to ameliorate renal injury induced by T2DM (Lachin et al., 2011), thioacetamide-induced hepatotoxicity (Al-Hashem et al., 2019a), liver injury in T2DM associated with dyslipidemia (Matafome et al., 2011), aortopathy and hypertension (Dallak et al., 2019), and heart failure (Dziubak et al., 2018); and (ii) captopril was reported to inhibit lipid peroxidation and inflammationin liver injury (Al-Hashem et al., 2019a) and inhibit platelet aggregation and thrombus formation (Higashi et al., 2005). In addition, both compounds were reported (i) to protect against mitochondrial damage and reactive oxygen species production induced in chondrocytes under interleukin-1 $\beta$ (IL-1 $\beta$ ) stimulation using primary murine chondrocytes (Wang et al., 2019a); (ii) to improve osteopenia and promotes bone formation in cultured primary osteoblasts (Liu et al., 2011); and (iii) decreased the pathology of osteoarthritis-induced osteoarticular injury in rats (Tang et $a l .$, 2015). Therefore, we speculated that a combination of metformin and captopril can efficiently protect against diabetes-induced OA, associated with the inhibition of glycemia, dyslipidemia and biomarkers of inflammation.

\section{MATERIAL AND METHOD}

Animals. All rat studies were performed according to the Guide for the Care and Use of Laboratory Animals published by the US National Institutes of Health (NIH publication No. 85-23, revised 1996), and the King Khalid University Ethical Review Committee (Ethics Statement) approved this work.Albino male rats weighing 170 - 200 gm were used for this study. Animals were housed under a controlled temperature of $23 \pm 1^{\circ} \mathrm{C}$, with a twelve hours light/dark cycle and had free access to food and water.

Experimental design. After a one week adaptation period, rats were allocated into 3 groups (8 / group) as follows: The nontreated control group (Control) of rats were injected intraperitoneally with vehicle and fed with a standard animal diet for 12 weeks. The diabetic group or the model group
(T2DM): to induce diabetes, rats were fed on a high carbohydrate and fat diets (HCFD) (Collino et al., 2010) for two weeks and then was given a single injection of streptozotocin (STZ, $50 \mathrm{mg} / \mathrm{kg}$ body weight), and continued on a HCFD until being sacrificed at the end of the experiment. The Met+T2DM group: to investigate the effects of metformin plus resveratrol on OA, rats were treated with Met $(200 \mathrm{mg} /$ $\mathrm{kg}$ body weight) plus Cap ( $150 \mathrm{mg} / \mathrm{kg}$ body weight $)$ and fed on a HCFD from day 1 till the end of the investigation at week 12 and injected with STZ at day 14 as before. Tail bleeds were performed one week post STZ injection to confirm hyperglycemia by measuring the levels of fasting blood glucose (>200 mg/dL) using a Randox reagent kit (SigmaAldrich). At week 12, rats were euthanized and blood samples were collected by cardiac puncture. Tissues were then harvested. Sera were separated and stored at $-20{ }^{\circ} \mathrm{C}$ for measuring biochemical parameters.

Histological study. Knee joints specimens were dissected and immediately fixed with $10 \%$ formol saline for 72 hours prior to decalcification for three weeks using $5 \%$ hydrochloric acid. Specimens were then dehydrated with alcohols and paraffin embedding using standard methods. Tissue specimens were then sectioned in sagittal plane with $5 \mathrm{~mm}$ thickness and were stained with H\&E, and analyzed to observe the morphological and pathological changes using light microscopy. The mean thickness of the articular cartilage surface was evaluated in all groups of rats.

Determination of blood levels of glucose, $\mathrm{HbA} 1 \mathrm{c}, \mathrm{TG}$, CHOL, LDL-C, HDL-C, hs-CRP, TNF- $\alpha$ and IL-6. Blood levels of glucose were determined colorimetrically using a Randox reagent kit (Sigma-Aldrich). Blood levels of HbA1c were measured using ELISA kit Cat. No. 80300; Crystal Chem, Inc., IL, USA). The concentrations of serum total cholesterol (CHOL), triglyceride (TG), low density lipoprotein-cholesterol (LDL-C), high density lipoproteincholesterol (HDL-C) were measured using the corresponding commercial enzyme kits (HUMAN Diagnostics, Wiesbaden, Germany). Serum levels of C-reactive protein (hs-CRP, ELISA kit Cat. No. ERC1021-1; ASSAYPRO, USA), TNFa (ELISA kit BIOTANG INC, Cat. No. R6365, MA, USA), and IL-6 (ELISA kit BIOTANG INC, Cat. No. RB1829, MA, USA) were used as recommended by the manufacturer.

Statistical analysis and morphometry. The data were expressed as the mean \pm standard deviation (SD). Data were processed and analyzed using the SPSS version 10.0 (SPSS, Inc., Chicago, Ill., USA). One-way ANOVA was done followed by Tukey's post hoc test. Pearson correlation statistical analysis was done for detection of a probable significance between two different parameters. Results were considered significant if $\mathrm{p} \leq 0.05$. 
Using "Leica Qwin 500 C" image analyzer (Cambridge, UK), the articular cartilage thickness score was obtained in 10 non overlapping high power fields/ rat of H\&E sections. Quantitative data were tabulated as means and standard deviations (SD) and compared using analysis of variance (ANOVA) followed by post-Hoc analysis (Tukey test). Significant difference was considered when P-value $<0.05$. Calculations were made on SPSS software (version 19).

\section{RESULTS}

Metformin plus captopril protect against diabetesinduced OA. To evaluate the effect of Met+Cap treatment on protection against diabetes-induced OA using the basic histology staining method, one group of diabetic rats was treated with Met+Cap for 12 weeks, and knee joint tissues harvested from all animal groups were prepared for $\mathrm{H} \& \mathrm{E}$ staining. Representative H\&E image of the articular cartilage knee joint obtained from the control group (Fig. 1A) shows a normal knee joint architecture as demonstrated by intact smooth articular surface with small flattened chondrocytes, regular chondrocytes surrounded by lacunae are scattered in the territorial matrix of the deeper tissue, and a clear tide mark bridges between the deep zone and the calcified cartilage. Furthermore, bone marrow cavity and the subchondral bone can be seen. Whereas, the data obtained from the diabetic untreated rats (Figs. 1B and 1D) showed a substantial damage to the articular cartilage presented by a very thin and irregularly eroded articular surface, profound damage to the tide mark that separate the deep zone from the calcified zone, and abnormal bone marrow cavities and remodeling of the subchondral bone. Treatment of the diabetic rats with Met+Cap (Fig. 1C and 1D) substantially protected the knee joint articular cartilage. This is confirmed by H\&E image (Figs. 1C ) and histograms represent a quantitative analysis of the mean articular cartilage thickness (Fig. 1D) showing an increase in the thickness of the articular cartilage with normal smooth superficial region, observed tide mark (bifid arrow) between the deep zone and the calcified zone and normal subchondral bone remodeling (star).
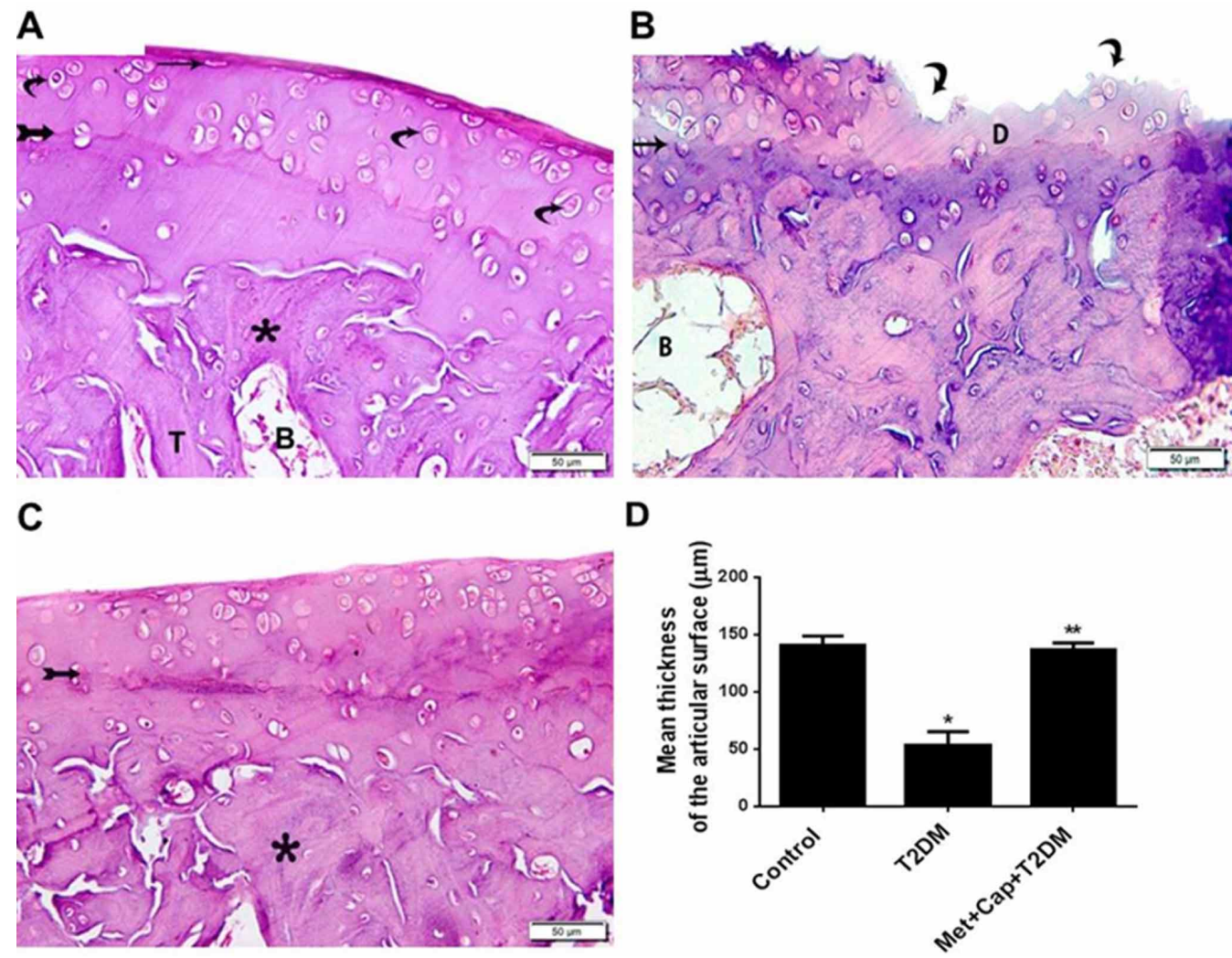

Fig. 1.Suppression of T2DM-induced OA by metformin (Met) plus captopril (Cap). H\&E stained images (x200)of knee joint tissues harvested at week 12 from the control group (A), T2DM group (B), and the protective group, Met+Cap+ T2DM (C). Note that in (A), arrows point to chondrocytes located above the tide mark, and bifid arrows in (A and C) points to the tide mark separating the calcified zone from the deep zone.The asterisks in (A) and (D) point to the normal subchondral bone remodeling, and curved arrows in (C) point to the damaged articular surface. H\&E: hematoxylin and eosin; T2DM: type 2 diabetes mellitus; Abbreviations: B, bone marrow cavities; $\mathrm{D}$, the deep zone. Histograms in (D) represent a quantitative analysis of the mean articular cartilage thickness from the above three animal groups. All shown $\mathrm{p}$ values are significant; $* \mathrm{p}<0.05$ versus control and $* * \mathrm{p}<0.05$ versus T2DM. 
Induction of diabetes and dyslipidemia is inhibited by metformin plus captopril. In view of the results described above that showed substantial protection to the knee joint articular cartilage in the group of rats treated with Met+Cap, we assessed the blood levels of biomarkers of diabetes (glucose and glycated hemoglobin) and dyslipidemia (TG, CHOL, LDL-C, and HDL-C) in all animal groups. As shown in Figure 2, diabetes caused a sharp increase in blood glucose (Fig. 2A), HbA1c (Fig. 2B), TG (Fig. 2C), CHOL (Fig. 2D), and LDL-C (Fig. $2 \mathrm{E})$ that was significantly $(\mathrm{p} \leq 0.0013)$ decreased by Met+Cap. Whereas, diabetes decreased blood levels of HDL-C, which was significantly $(\mathrm{p}<0.0001)$ increased by Met+Cap (Fig. 2F). However, the effects of Met+Cap were still significant $(p<0.05)$ when compared with the control group, except (B) and (C).
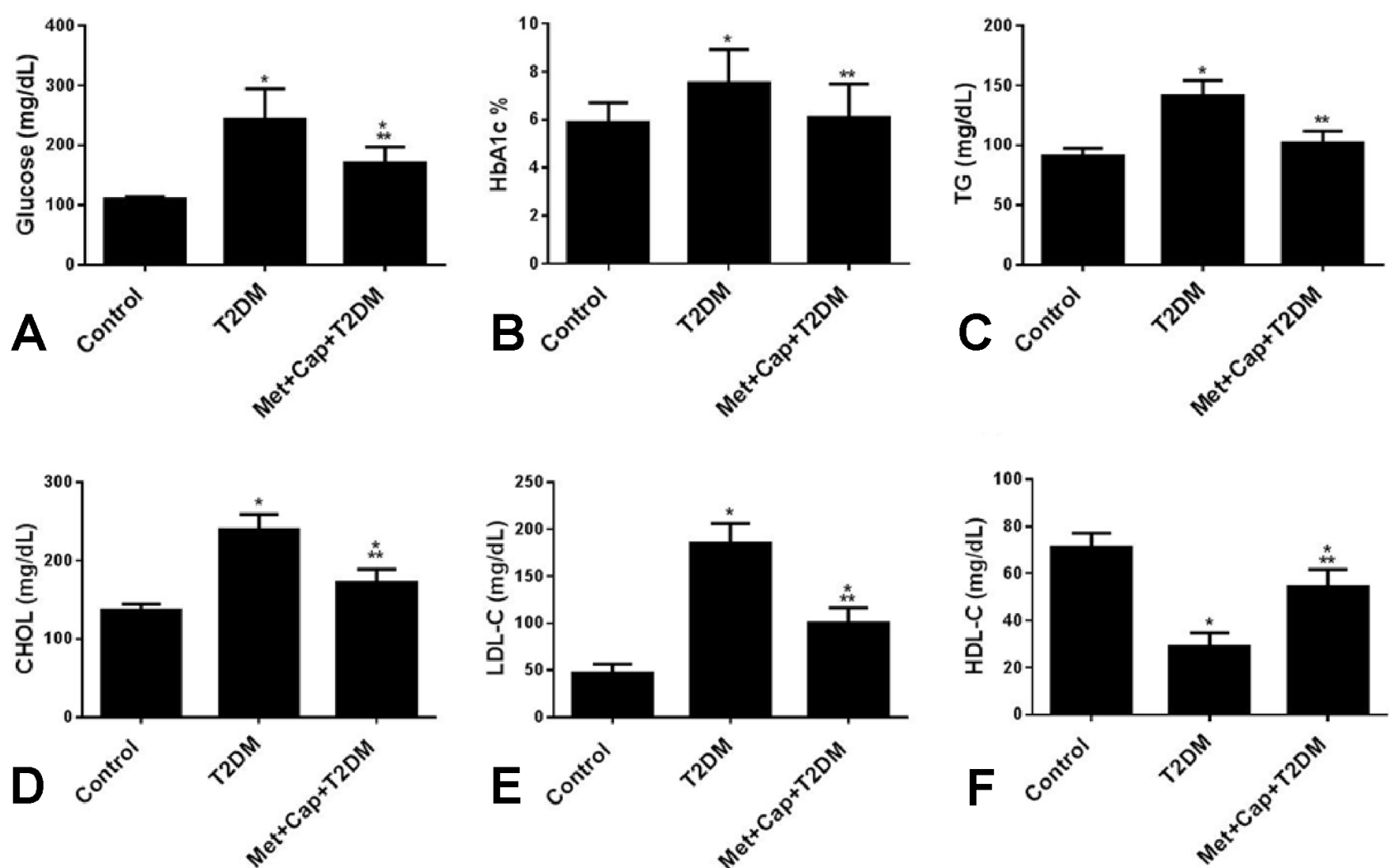

Fig. 2. Metformin (Met) plus captopril (Cap) decrease hyperglycemia, glycated haemoglobin, and dyslipidemia induced by T2DM. Serum levels of glucose (A), HbA1c (B), TG (C), CHOL (D), LDL-C (E), and HDL-C (F) were measured at week 12 in all groups of rats; Control, T2DM, and (Met+Cap+T2DM) groups. Results represent the mean $( \pm \mathrm{SD}) ; \mathrm{n}=8$ for each group. ${ }^{*} \mathrm{p}<0.05$ versus control, ${ }^{*} \mathrm{p}<00.05$ versus T2DM.T2DM: type 2 diabetes mellitus; HbA1c: glycated hemoglobin; TG:triglyceride; CHOL: total cholesterol; LDL-C:low density lipoprotein-cholesterol; HDL-C: high density lipoproteincholesterol.

Metformin plus captopril ameliorates inflammation in diabetes-induced OA. The link between $\mathrm{OA}$ and inflammation is well-known (Marouf et al., 2018). To investigate whether the observed protection of $\mathrm{OA}$ by Met+cap was also associated with the inhibition of biomarkers of inflammation, we measured hs-CRP, IL-6, and TNF- $\alpha$ in blood samples collected from all animal groups 10 weeks post diabetic induction (Fig. 3). Blood levels of hs-CRP (Fig. 3A), IL-6 (Fig. 3B), and TNF- $\alpha$ (Fig. 3C) were significantly $(p<0.0001)$ higher in the diabetic group compared with the control group. Met+Cap treatment for 12 weeks significantly $(\mathrm{p}<0.05)$ decreased diabetes-induced biomarkers of inflammation. However, the effects of Met+Cap were still significant $(p<0.05)$ when compared with the control group, which means partial inhibition.

Correlation between the territorial matrix cartilage damageand biomarkers of diabetes, dyslipidemia, and inflammation. We further determined the correlation between the mean thickness of the articular surface scoring and the blood levels of glucose, HbA1c, TG, LDL-C, HDL- 
$\mathrm{C}$, and hs-CRP in order to draw a link between the pathogenesis of T2DM-induced OA and these biomarkers and to confirm and characterize that the role of the agents Met+Cap is stable and appropriate in OA. Mean thickness of the articular cartilage score showed negative correlation with glucose $(r=-0.761 ; p<0.0001)$ (Fig. 4A), HbA1c $(\mathrm{r}=-0.556 ; \mathrm{p}=0.0014)($ Fig. $4 \mathrm{~B}), \mathrm{TG}(\mathrm{r}=-0.869$ $\mathrm{p}<0.0001)$ (Fig. 4C), LDL-C ( $\mathrm{r}=-0.890 ; \mathrm{p}<0.0001)$ (Fig. 4D), and hs-CRP ( $\mathrm{r}=-0.692 ; \mathrm{p}<0.0001)$ (Fig. 4F). Whereas, Mean thickness of the articular cartilage displayed positive correlation with HDL-C ( $\mathrm{r}=0.870$; $\mathrm{p}<0.0001)($ Fig. 4E).
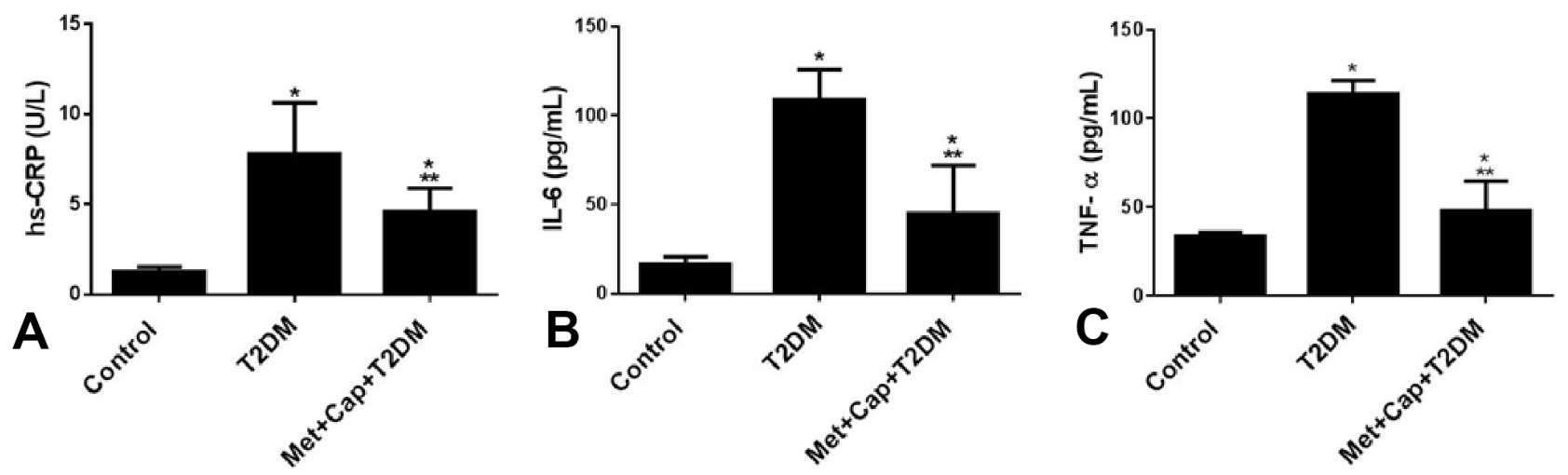

Fig. 3. Metformin (Met) plus captopril (Cap) decrease biomarkers of inflammation induced by T2DM. Serum levels of hsCRP (A), IL-6 (B), and TNF-a (C) were measured at week 12 in all groups of rats; Control, T2DM, and (Met+Cap+T2DM) groups. Results represent the mean $( \pm \mathrm{SD}) ; \mathrm{n}=8$ for each group. ${ }^{*} \mathrm{p}<0.05$ versus control, ${ }^{*}{ }^{*} \mathrm{p}<0.05$ versus T2DM. T2DM: type 2 diabetes mellitus; hs-CRP: high sensitivity C-reactive protein; IL-6: interleukin- 6; TNF-a: tumor necrosis factor alpha.

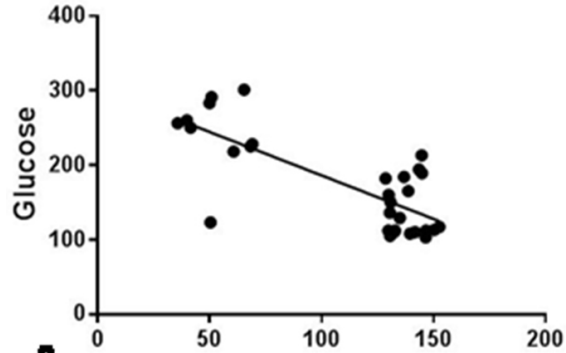

A Thickness of the articular cartilage

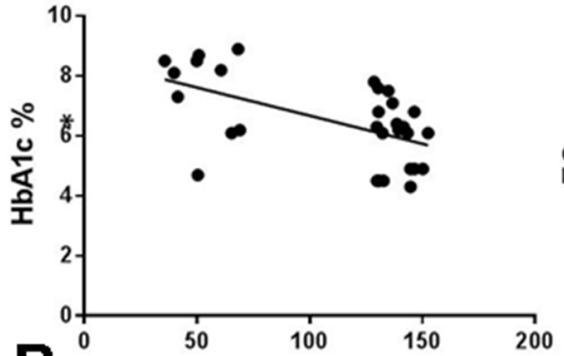

B Thickness of the articular cartilage

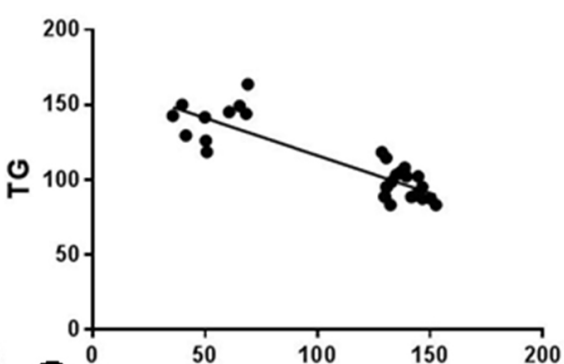

Thickness of the articular catilage
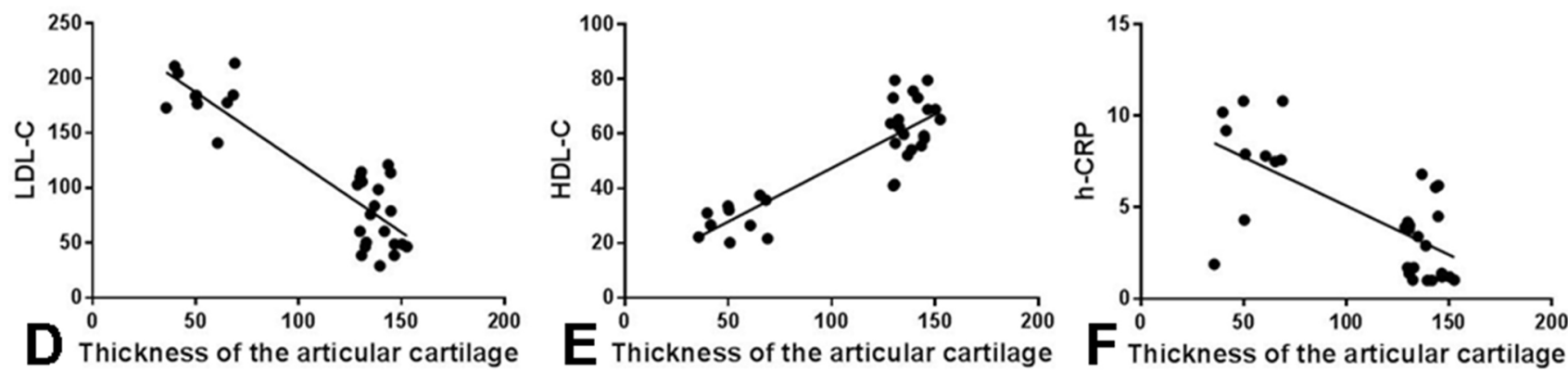

Fig. 4. Correlation between the mean thickness of the articular cartilage surface score and biomarkers of diabetes, dyslipidemia, and inflammation. The articular cartilage thickness score was measured in all groups of rats at week 12 and its correlation with glucose, HbA1c, TG, LDL-C, HDL-C, and hs-CRP are shown (A-F). HbA1c: glycated hemoglobin; TG:triglyceride; LDL-C: low density lipoprotein-cholesterol; HDL-C: high density lipoprotein-cholesterol; hs-CRP: high sensitivity Creactive protein. 


\section{DISCUSSION}

The main objective of our study was to investigate whether the combined metformin and captopril can effectively protect against diabetes-induced knee joint injury and augmentations of biomarkers of diabetes, dyslipidemia, and inflammation. Therefore, we induced knee joint OA secondary to diabetes in rats and then treated one diabetic group daily with Met+Cap for 12 weeks before being sacrificed. The main findings of this study were that Met+Cap significantly inhibits knee joint injury secondary to type 2 diabetes mellitus in a rat model of diabetes-induced OA (Fig. 1). In addition, Met+Cap treatment partially controlled glycemia, dyslipidemia, and inflammation (Figs. 2 and 3). Furthermore, our data that shows a positive correlation between articular cartilage thickness score and glycemia, dyslipidemia, and inflammation (Fig. 4) support our conclusion mentioned above. Therefore, our results were thus consistent with our working hypothesis that the combined metformin and captopril, can substantially protect against knee joint damage caused in a rat model of diabetes-induced OA.

The link between knee osteoarthritis and diabetes and inflammation is well established in animal models and human (Al-Hashem et al., 2017; Perez Vertti et al., 2018), and our H\&E images (Fig. 1) and blood chemistry data (Figs. 2 and 3 ) confirm the development of knee OA and inflammation as one of the diabetic complications occurring 10 weeks postdiabetic induction in rats, are in agreement with these reports. In addition, our data that point to a profound damage in the knee joint cartilage (Figs. 1 and 4) secondary to diabetes in rats together with the report that demonstrated diabetes increased osteoclast activity and bone loss, which increased the risk of bone fractures and poor fracture healing (Kalaitzoglou et al., 2016), are in agreement with the previously published work that showed collagen accounts for about forty percent of the articular cartilage territorial matrix (Eyre, 2002), and stimulation of collagen type II production delayed articular cartilage degradation in OA (Lu et al., 2019). Furthermore, our data that point to Met+Cap inhibition of knee joint $\mathrm{OA}$ as demonstrated by a significant amelioration of articular cartilage damage in rats are in agreement with the reports that show metformin reduced the risk of total knee joint replacement in obese patients with knee OA (Wang et al., 2019b), and exerted a chondroprotective effect in cultured chondrocytes (Wang et al., 2019a).

In conclusion, using basic histology and blood chemistry approaches, we demonstrate the development of OA secondary to diabetes mellitus in a rat model, which is significantly protected by a combination of metformin and captopril for a period of 10 weeks post-diabetic induction.

\section{ACKNOWLEDGEMENTS}

The support and input of Dr. Samaa S. Kamar from the Department of Medical Histology, Kasr Al-Aini Faculty of Medicine, Cairo University, Cairo, Egyptis highly appreciated by the author of this work. We are also grateful to Dr Mariam Al-Ani from Face Studio Clinic, 273 Hagley Road, Birmingham, B16 9NB, UK for proofreading the manuscript.

EL-BIDAWY, M. H.; AL-ANI, B.; HUSSAIN, A. B.O.; ALGHAMDI, S.; ALDOSSARI, K. K. \& HAIDARA, M. A Inhibición de la lesión de la articulación de la rodilla inducida por diabetes mellitus en ratas mediante una combinación de metformina y captopril. Int. J. Morphol., 39(3):747-753, 2021.

RESUMEN: La osteoartritis (OA) es una enfermedad inflamatoria que daña las articulaciones y afecta a millones de personas en todo el mundo. No se han investigado los posibles efectos inhibidores del fármaco antidiabético metformina combinado con captopril, el inhibidor de la enzima convertidora de angiotensina, sobre el daño inducido por la diabetes en el cartílago articular de la articulación de la rodilla asociado con la inhibición de la glucemia, dislipidemia e inflamación. En este estudio fue inducida la diabetes en ratas con dietas altas en carbohidratos y grasas y una sola inyección de estreptozotocina $(50 \mathrm{mg} / \mathrm{kg}$ ). El grupo protector de ratas se pretrató con dosis diarias combinadas de metformina (Met; $200 \mathrm{mg} / \mathrm{kg}$ de peso corporal) y captopril (Cap; $150 \mathrm{mg} / \mathrm{kg}$ de peso corporal) durante 14 días antes de la inducción diabética. El tratamiento se continuó con metformina y resveratrol hasta el final del experimento en la semana 12. Los tejidos obtenidos de las articulaciones de la rodilla se prepararon para la tinción de histología básica con hematoxilina y eosina (H\&E) y se examinaron con microscopía óptica. Imágenes representativas de H\&E mostraron que la OA se desarrolló en las ratas diabéticas, como lo evidencia un daño profundo en las articulaciones de la rodilla, como la erosión irregular y una fuerte disminución en el grosor de la superficie del cartílago articular y remodelación anormal del hueso subcondral que fueron mejorados sustancialmente por Met + Cap. Met + Cap. También redujo significativamente ( $p$ $<0.05)$ los niveles sanguíneos de glucosa, hemoglobina glicosilada (HbA1c), dislipidemia y los biomarcadores inflamatorios, proteína $\mathrm{C}$ reactiva de alta sensibilidad (hs-CRP), interleucina-6 (IL-6), $y$ factor de necrosis tumoral alfa (TNF- $\alpha$ ) inducido por diabetes. Además, una correlación significativa $(\mathrm{p} \leq 0,0014)$ entre el grosor del cartílago articular y los niveles sanguíneos de glucosa, HbA1c, triglicéridos (TG), lipoproteínas-colesterol de baja densidad (LDLC), lipoproteínas de alta densidad-colesterol (HDL-C) ) y hs-CRP. Así, demostramos que Met + Cap protege eficazmente la articulación de la rodilla contra lesiones inducidas por diabetes en ratas, posiblemente debido a la inhibición de la glicemia, dislipidemia y biomarcadores de inflamación.

PALABRAS CLAVE: Artrosis; Diabetes; Articulación de la rodilla; Metformina; Captopril; Modelo de rata. 


\section{REFERENCES}

Al-Hashem, F.; Al Humayed, S.; Haidara, M. A.; Abdel Latif, N. S. \& AlAni, B. Captopril suppresses hepatic mammalian target of rapamycin cell signaling and biomarkers of inflammation and oxidative stress in thioacetamide-induced hepatotoxicity in rats. Arch. Physiol. Biochem., $1-8,2019 \mathrm{~b}$.

Al-Hashem, F.; Al-Humayed, S.; Amin, S. N.; Kamar, S. S.; Mansy, S. S.; Hassan, S.; Abdel-Salam, L. O.; Ellatif, M. A.; Alfaifi, M.; Haidara, M. A.; et al. Metformin inhibits mTOR-HIF-1a axis and profibrogenic and inflammatory biomarkers in thioacetamide-induced hepatic tissue alterations. J. Cell. Physiol., 234(6):9328-37, 2019a.

Al-Hashem, F.; El Karib, A. O.; Bin-Jaliah, I.; Dallak, M.; Sakr, H. F.; Eid, R. A.; Zaki, M. S. A.; Al-Shamsi, M.; Haidara, M. A. \& Al-Ani, B. Exercise protects against insulin-dependent diabetes-induced osteoarthritis in rats: A scanning electron microscopy study. Ultrastruct. Pathol., 41(3):252-7, 2017.

Berenbaum, F. Diabetes-induced osteoarthritis: from a new paradigm to a new phenotype. Ann. Rheum. Dis., 70(8):1354-6, 2011.

Cicero, A. F. G.; Tartagni, E. \& Ertek, S. Metformin and its clinical use: new insights for an old drug in clinical practice. Arch. Med. Sci., 8(5):907-17, 2012.

Collino, M.; Aragno, M.; Castiglia, S.; Miglio, G.; Tomasinelli, C.; Boccuzzi, G.; Thiemermann, C. \& Fantozzi, R. Pioglitazone improves lipid and insulin levels in overweight rats on a high cholesterol and fructose diet by decreasing hepatic inflammation. Br. J. Pharmacol., 160(8):1892902, 2010.

Dallak, M.; Haidara, M. A.; Bin-Jaliah, I.; Eid, R. A.; Amin, S. N.; Abdel Latif, N. S. \& Al-Ani, B. Metformin suppresses aortic ultrastrucural damage and hypertension induced by diabetes: a potential role of advanced glycation end products. Ultrastruct. Pathol., 43(4-5):190-8, 2019.

Dziubak, A.; Wójcicka, G.; Wojtak, A. \& Be?towski, J. Metabolic effects of metformin in the failing heart. Int. J. Mol. Sci., 19(10):2869, 2018.

Eyre, D. Collagen of articular cartilage. Arthritis Res., 4(1):30-5, 2002.

Hayami, T. Osteoarthritis of the knee joint as a cause of musculoskeletal ambulation disability symptom complex (MADS). Clin. Calcium, 18(11):1574-80, 2008.

Higashi, Y.; Chayama, K. \& Yoshizumi, M. Angiotensin II type I receptor blocker and endothelial function in humans: role of nitric oxide and oxidative stress. Curr. Med. Chem. Cardiovasc. Hematol. Agents, 3(2):133-48, 2005.

Kalaitzoglou, E.; Popescu, I.; Bunn, R. C.; Fowlkes, J. L. \& Thrailkill, K. M. Effects of type 1 diabetes on osteoblasts, osteocytes, and osteoclasts. Curr. Osteoporos. Rep., 14(6):310-9, 2016.

Lachin, J. M.; Viberti, G.; Zinman, B.; Haffner, S. M.; Aftring, R. P.; Paul, G.; Kravitz, B. G.; Herman, W. H.; Holman, R. R.; Kahn, S. E.; et al. Renal function in type 2 diabetes with rosiglitazone, metformin, and glyburide monotherapy. Clin. J. Am. Soc. Nephrol., 6(5):1032-40, 2011.

Liu, Y. Y.; Yao, W. M.; Wu, T.; Xu, B. L.; Chen, F. \& Cui, L. Captopril improves osteopenia in ovariectomized rats and promotes bone formation in osteoblasts. J. Bone Miner. Metab., 29(2):149-58, 2011.

Lu, W.; Ding, Z.; Liu, F.; Shan, W.; Cheng, C.; Xu, J.; He, W.; Huang, W.; Ma, J. \& Yin, Z. Dopamine delays articular cartilage degradation in osteoarthritis by negative regulation of the NF-kB and JAK2/STAT3 signaling pathways. Biomed. Pharmacother, 119:109419, 2019.

Marouf, B. H.; Hussain, S. A.; Ali, Z. S. \& Ahmmad, R. S. Resveratrol supplementation reduces pain and inflammation in knee osteoarthritis patients treated with meloxicam: a randomized placebo-controlled study. J. Med. Food, 21(12), 2018. DOI: https://www.doi.org/10.1089/ jmf. 2017.4176

Matafome, P.; Louro, T.; Rodrigues, L.; Crisóstomo, J.; Nunes, E.; Amaral, C.; Monteiro, P.; Cipriano, A. \& Seiça, R. Metformin and atorvastatin combination further protect the liver in type 2 diabetes with hyperlipidaemia. Diabetes Metab. Res. Rev., 27(1):54-62, 2011.
Moussa, S. A. Oxidative stress in diabetes mellitus. Rom. J. Biophys., 18:225-36, 2008

Perez Vertti, R. D. A.; Muñiz, L. S. A.; Martínez, J. M.; Galarza, F. F. G. \& Astorga, R. A. Cartilage oligomeric matrix protein levels in type 2 diabetes associated with primary knee osteoarthritis patients. Genet. Test Mol. Biomarkers, 23(1):16-22, 2019.

Pottie, P.; Presle, N.; Terlain, B.; Netter, P.; Mainard, D. \& Berenbaum, F. Obesity and osteoarthritis: more complex than predicted! Ann. Rheum. Dis., 65(11):1403-5, 2006.

Scanzello, C. R. \& Goldring, S. R. The role of synovitis in osteoarthritis pathogenesis. Bone, 51(2):249-57, 2012.

Shoelson, S. E.; Lee, J. \& Goldfine, A. B. Inflammation and insulin resistance. J. Clin. Invest., 116(7):1793-801, 2006.

Tang, Y.; Hu, X. \& Lu, X. Captopril, an angiotensin-converting enzyme inhibitor, possesses chondroprotective efficacy in a rat model of osteoarthritis through suppression local renin-angiotensin system. Int. J. Clin. Exp. Med., 8(8):12584-92, 2015.

Vistoli, G.; De Maddis, D.; Cipak, A.; Zarkovic, N.; Carini, M. \& Aldini, G. Advanced glycoxidation and lipoxidation end products (AGEs and ALEs): an overview of their mechanisms of formation. Free Radic. Res., 47 Suppl. 1:3-27, 2013.

Wang, C.; Yang, Y.; Zhang, Y.; Liu, J.; Yao, Z. \& Zhang, C. Protective effects of metformin against osteoarthritis through upregulation of SIRT3-mediated PINK1/Parkin-dependent mitophagy in primary chondrocytes. Biosci. Trends, 12(6):605-s12, 2019a.

Wang, Y.; Hussain, S. M.; Wluka, A. E.; Lim, Y. Z.; Abram, F.; Pelletier, J. P.; Martel-Pelletier, J. \& Cicuttini, F. M. Association between metformin use and disease progression in obese people with knee osteoarthritis: data from the Osteoarthritis Initiative-a prospective cohort study. Arthritis Res. Ther, 21(1):127, 2019b.

\section{Corresponding author: \\ Prof. Mohamed A Haidara \\ Department of Physiology \\ Kasr Al-Aini Faculty of Medicine \\ Cairo University \\ Cairo \\ EGYPT}

E-mail: haidaram@hotmail.com

Received: 29-12-2020

Accepted: 14-03-2021 